\title{
Body size adaptions under climate change: zooplankton community more important than temperature or food abundance in model of a zooplanktivorous fish
}

\author{
Gabriella Ljungström ${ }^{1, *}$, Marion Claireaux ${ }^{2}$, Øyvind Fiksen ${ }^{1}$, Christian Jørgensen ${ }^{1}$ \\ ${ }^{1}$ Department of Biological Sciences, University of Bergen, 5006 Bergen, Norway \\ ${ }^{2}$ Institute of Marine Research, 5817 Bergen, Norway
}

\begin{abstract}
One of the most well-studied biogeographic patterns is increasing body size with latitude, and recent body size declines in marine and terrestrial organisms have received growing attention. Spatial and temporal variation in temperature is the generally invoked driver but food abundance and quality are also emphasized. However, the underlying mechanisms are not clear and the actual cause is likely to differ both within and among species. Here, we focused our attention on drivers of body size in planktivorous fish that forage through vision. This group of organisms plays a central role in marine ecosystems by linking the energy flow from lower to higher trophic levels. Using a model that incorporates explicit mechanisms for visionbased feeding and physiology, we investigated the influence on optimal body size of several biotic (prey size, prey energy content, and prey biomass concentration) and abiotic (temperature, latitude, and water clarity) factors known to affect foraging rates and bioenergetics. We found prey accessibility to be the most influential factor for body size, determined primarily by prey size but also by water clarity, imposing visual constraints on prey encounters and thereby limiting feeding rates. Hence, for planktivores that forage through vision, an altered composition of the prey field could have important implications for body size and for the energy available for reproduction and other fitness-related tasks. Understanding the complicated effects of climate change on zooplankton communities is thus crucial for predicting impacts on planktivorous fish, as well as consequences for energy flows and body sizes in marine systems.
\end{abstract}

${ }^{*}$ Corresponding author: gabriella.ljungstrom@uib.no

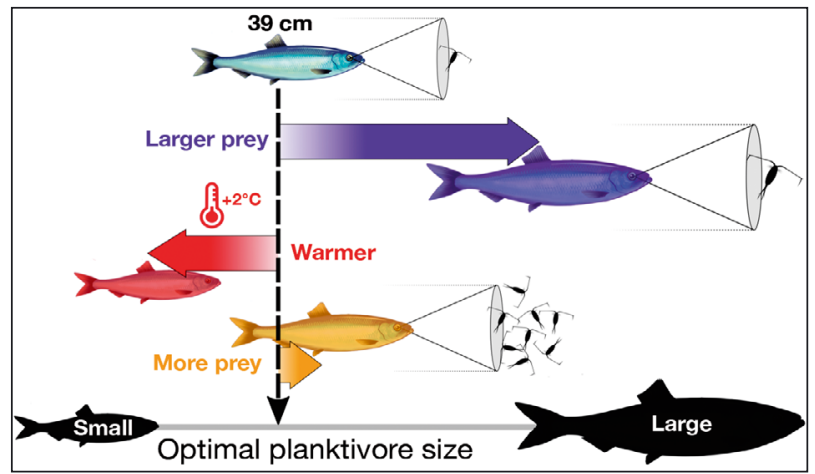

Prey size has a large effect on planktivore energetics and optimal body size, whereas temperature and prey biomass concentration play a smaller role.

Illustration: Tom Langbehn

KEY WORDS: Optimal body size $\cdot$ Planktivore $\cdot$ Visual foraging $\cdot$ Wasp-waist $\cdot$ Zooplankton community

\section{INTRODUCTION}

Why are there organisms of different body size? What causes size variation among organisms that otherwise occupy similar ecological niches? Size variation has received abundant attention because it is so readily observable, and sweeping theories that squeeze all species into one explanation abound. In this paper, we argue that variation in body size can also serve as a lens through which a more nuanced picture may emerge. By acknowledging that observed size differences can reflect local adaptation, scrutinizing environmental differences can uncover

() The authors 2020. Open Access under Creative Commons by Attribution Licence. Use, distribution and reproduction are unrestricted. Authors and original publication must be credited. 
the potential ecological drivers that constrain energetics, growth, and life histories. But before we can delve into one species in detail, we need to establish the null expectations from established theories for biogeographic clines in body size.

The tendency of organisms to be smaller at higher temperatures and lower latitudes is one of the most well studied biogeographic patterns, and biologists have long been trying to explain the underlying mechanisms (discussed in Blackburn et al. 1999, Angilletta et al. 2004, Millien et al. 2006, Teplitsky \& Millien 2014). Two common hypotheses link size differences directly to temperature, through Bergmann's rule (Bergmann 1847) and the temperature-size rule (Atkinson 1994, Angilletta \& Dunham 2003, Kingsolver \& Huey 2008). The former relates body size to thermoregulatory capacity in endotherms (Bergmann 1847), whereas the latter describes the effect of temperature on growth and maturation in ectotherms (Atkinson 1994). Apart from temperature, latitudinal and seasonal variation in food availability and quality is often invoked to explain why body size varies in time and space (see references in McNab 2010, Watt et al. 2010, Teplitsky \& Millien 2014, Vinarski 2014). For example, larger body size at higher latitudes could be an adaptation to reduce the risk of overwinter starvation (Cushman et al. 1993) or a consequence of less competition for resources due to higher density-independent mortality and fewer species associated with strongly seasonal environments (Blackburn et al. 1999).

Reduction in body size is evident in a growing number of species, comprising endotherms and ectotherms in terrestrial and aquatic environments (Gardner et al. 2011, Sheridan \& Bickford 2011). The scale and geographic pattern of this trend make body size declines the third universal response to climate change, after shifting spatial distributions and altered phenologies (Daufresne et al. 2009, Gardner et al. 2011, Sheridan \& Bickford 2011, Cheung et al. 2013). This trend is particularly strong in aquatic environments (Forster et al. 2012, Horne et al. 2015) and, although harvesting is likely partly responsible, current rates of decline are faster than expected from fishing alone (Baudron et al. 2011, Audzijonyte et al. 2013). In addition to Bergmann's rule and the temperature-size rule, warming-related constraints on aerobic respiration have been invoked to cause size reductions in aquatic species that breathe with gills or similar structures (Pauly 1981, Atkinson et al. 2006, Cheung et al. 2011, Verberk et al. 2011, Forster et al. 2012), but this hypothesis has received criticism (e.g. Brander et al. 2013, Lefevre et al. 2017, summarized in Audzijonyte et al. 2019).
Contrary to the directional effect of temperature, climate-change-induced alterations in food resources can lead to both smaller and larger size (Millien et al. 2006, Gardner et al. 2011, Teplitsky \& Millien 2014). For example, a decrease in food availability or quality can restrict energy acquisition and lead to smaller size, whereas a longer growing season may extend foraging opportunities and thus increase growth potential. Moreover, in ectotherms, both digestion and metabolic rate are influenced by temperature, meaning that the net effect of warming on energy surplus depends on the relative magnitude of these 2 factors, as well as on food availability.

Identifying the underlying drivers of spatial and temporal variation in body size is crucial for understanding its origins, and for predicting how this trait will respond to environmental change. However, since many environmental factors are correlated and some are changing in parallel over time, without a causal link between them, disentangling their relative effects on body size variation is inherently difficult (Blackburn et al. 1999, Millien et al. 2006, Gardner et al. 2011, Teplitsky \& Millien 2014, Audzijonyte et al. 2019). A useful tool for assessing causality is mechanistic modeling, whereby functional relationships are used to predict a system's behavior. Undoubtedly, intra- and inter-specific body size clines are not determined by one, but several different mechanisms (Blackburn et al. 1999, Angilletta \& Dunham 2003, Angilletta et al. 2004, Millien et al. 2006). Therefore, to compare general explanations with the details relating to particular ecological lifestyles, we focused this study on drivers of body size in one group of aquatic ectotherms: zooplanktivorous fish that forage through vision.

Planktivorous fish, often collectively referred to as forage fish, play a central role in aquatic ecosystems since nearly all energy from lower to higher trophic levels flows through them (Alder et al. 2008). They are highly specialized for feeding on small zooplankton and are themselves key prey for larger fish, sea birds, and marine mammals. Using a model that incorporates explicit mechanisms for vision-based feeding and physiology, we investigated the influence on optimal body size from several biotic and abiotic factors known to affect foraging rates and bioenergetics. We modeled proximate effects on the energy budget of different sized individuals and interpreted our findings in light of the consequence for optimal body size. We defined optimal body size as the length at which annual surplus energy is maximized, representing the size at which the individual has the highest capacity of converting energy from 
the environment into reproductive output or other fitness-related tasks. Evolutionarily, this implies that individuals are expected to stop growing at this size, unless being larger or smaller has a considerable fitness advantage due to intra- and inter-specific interactions. For example, being larger could be optimal if this leads to an advantage in competition for food (Karplus et al. 2000) or mates (Kitano 1996), or if mortality declines strongly with size (Roff 1992, Charlesworth 1994). Conversely, maturation at a smaller size could be optimal if the prospects for survival and hence future reproduction are low (Michod 1979, Roff 1981). In this study, we focused on how bottom-up processes and abiotic factors affect optimal body size, and therefore omitted potential adaptations to predation risk and intra-specific interactions.

The Atlantic herring Clupea harengus is an appropriate study species for exploring the effects of bottom-up processes and abiotic factors on optimal body size; it is aquatic and long-lived. Aquatic organisms have an advantage over their terrestrial counterparts: they do not have to carry their body weight as tissue density is not very different from that of water (Schmidt-Nielsen 1997). Thus, environmental factors and selection pressures linked to bioenergetics are likely to cause larger variation in body size and therefore leave a more visible fingerprint. Further, organisms with long life spans presumably experience low predation, suggesting that energetic tradeoffs are the main constraint on reproduction and therefore have strong bearing on the evolution of body size. The wide distribution of Atlantic herring makes it highly suitable for studying environmental influences on geographic trait patterns; it is found across the North Atlantic from Spitsbergen in the north $\left(\mathrm{ca} .80^{\circ} \mathrm{N}\right)$ to the northern Bay of Biscay in the south (ca. $50^{\circ} \mathrm{N}$ ), and from the Baltic Sea in the east to southwestern Greenland, Labrador, and southward to South Carolina (ca. $30-70^{\circ} \mathrm{N}$ ) in the west (Whitehead 1985).

The present paper consists of 2 parts. First, a case study of herring in the Norwegian Sea and North Sea, aimed at identifying the underlying mechanisms responsible for the striking body size difference observed between herring in these 2 neighboring systems. The Norwegian Sea and the North Sea provide a good comparison since they vary in several characteristics proposed to influence body size, including water temperature, seasonality in production, prey community composition, and latitude. The second part is a detailed analysis to investigate the sensitivity of herring body size to variation in the abiotic (water temperature and light) and biotic environment (prey size, prey energy content, and prey biomass concentration). Our findings are therefore relevant for explaining geographic patterns and shifts in body size in visually foraging planktivores.

\section{MATERIALS AND METHODS}

To investigate how intrinsic and extrinsic factors come together to influence optimal body size, we combined 2 models: (1) a mechanistic model of prey encounter and foraging including light and vision and (2) a bioenergetics model for internal prey processing and energy budget. This coupled model captures feeding and the energy budget over the annual cycle as a function of body size and environmental settings. Feeding rate is influenced by prey properties (Fig. 1a,c), the diel cycle of irradiance (season and latitude; Fig. 1b), and optical properties of the water (Fig. 1d). More hours of light allow for more time feeding (Fig. 1b) and prey are easier to detect in clearer water, leading to higher encounter rates (Fig. 1d).

Herring detect larger prey at a longer distance, $R$, and because the volume searched scales with $R^{2}$ (Eq. 2 in Table 1), prey encounter rate is more sensitive to variation in prey size than prey biomass concentration. The visual acuity of fish tends to increase proportionally with eye size (Caves et al. 2017); this is included in our model (Eq. 7 in Table 1). Since swimming speed scales with body length (Eq. 2 in Table 1), the volume searched for prey scales with herring body length, $L^{3}$. Body mass also scales with $L^{3}$, but because beam attenuation blurs images exponentially with detection distance (Eqs. 4 and 5 in Table 1), there is a diminishing return of volume searched for large herring. This implies that the number of prey detected increases less than proportionally with herring body mass, which contributes to constraining the energy budget of larger fish. Finally, handling prey takes time and at some point this limits the rate at which prey can be ingested (Fig. 1a,c).

Internal constraints set by gut filling and digestion rate determine how much food can be digested, and this capacity also increases with size and with temperature (Fig. 1e). One of these processes, i.e. encounter rate, handling time, or digestion rate, always limits the acquisition rate. A further critical factor is that the rate of metabolism increases with temperature, so net energy surplus only goes up when temperature has a higher effect on acquisition through digestion than on metabolic loss (Fig. 1e). 

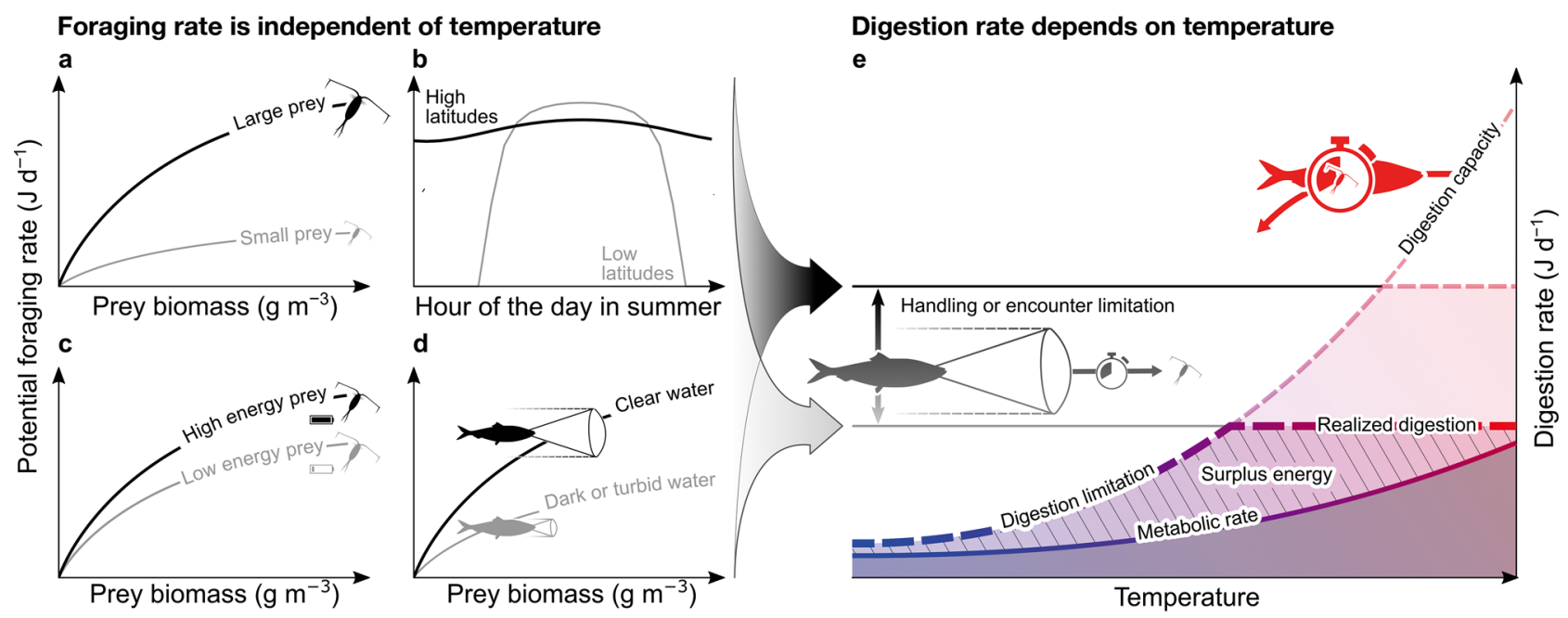

Fig. 1. Effect of $(\mathrm{a}, \mathrm{c})$ prey properties, (b) the diel cycle of irradiance (season and latitude), and (d) optical properties of the water on the potential foraging rate of herring, which is determined by (e) prey encounter or handling time limitation. Foraging rate is independent of temperature. Internal constraints set by gut filling and digestion rate determine how much food can be digested and this capacity increases with temperature (e). One of these processes (i.e. encounter rate, handling time, or digestion rate) always limits the acquisition rate ( $\mathrm{e}$; realized digestion). A critical factor for the energy budget is that metabolic rate increases with temperature, so net energy surplus only goes up when temperature has a higher effect on acquisition through digestion than on metabolic loss (e)

Whether it is feeding or digestive processes that eventually limit the body size of fish depends on a range of physiological traits and environmental factors; we have captured some of the most important ones in our model.

\subsection{Model of foraging and bioenergetics}

The output of the coupled foraging and bioenergetics model is an estimate of the annual surplus energy $\left(\mathrm{kJ} \mathrm{yr}^{-1}\right)$. This is the total annual energy intake minus all costs, computed for a range of adult body sizes $(10-45 \mathrm{~cm})$, which represents the energy available for growth and reproduction each year. We modeled the surplus energy for each day, $d$, and summed over all days to find the annual surplus. The procedure was repeated for each body length, $L$ :

$$
\varepsilon=\sum_{d=1}^{365}[U(d, L)-M(d, L)]
$$

where $U(d, L)$ is net energy uptake from feeding (kJ $\left.\mathrm{d}^{-1}\right)$, and $M(d, L)$ is the metabolic cost $\left(\mathrm{kJ} \mathrm{d}^{-1}\right)$. All equations leading to $U$ and $M$ are summarized in Table 1 . The following parameters were varied to determine their relative effects on optimal size: fish length, prey prosome length, prey energy content, prey biomass concentration, handling time, capture success, latitude, water temperature, and chlorophyll a (chl a) concentration.
The foraging model is a multiple-prey Holling Type II functional response where feeding rate satiates at high prey concentration (prey $\mathrm{m}^{-3}$ ) due to handling time limitation. The model estimates feeding rate as a function of prey characteristics, diel $(t$, hourly) and seasonal (daily) variation in solar irradiance, optical properties of the water, the visual acuity of the predator, and the capture success and handling time for prey (Eq. 1 in Table 1; Huse \& Fiksen 2010, Varpe \& Fiksen 2010). $M$ is modeled as a function of body weight and temperature with parameters estimated for Atlantic herring (weightdependence) and other clupeids (temperaturedependence) (Eq. 16 in Table 1; Rudstam 1988). We set the cost of swimming equal to the weight-dependent metabolic rate (Ware 1978) and assumed that herring swim at this rate $75 \%$ of the time in summer and $10 \%$ in winter (Eq. 17 in Table 1). Digestion and gut evacuation are complex processes that may depend on a number of factors, such as gut fullness, meal frequency, and prey characteristics. Since we could not find a relevant empirical relationship in the literature to describe these processes, we let one rate represent their aggregated effect (digestion rate; Eq. 13 in Table 1). We used the same parameters for sizeand temperature-dependency as for metabolic rate and calibrated the rate of digestion to annual surplus energy approximated from the data (see Section 1 in Supplement 1 at www.int-res.com/articles/suppl/ m636p001_supp1.pdf). 
Table 1. Equations used to model Atlantic herring body size (see Table 2 for variables and parameters; NWG: Norwegian Sea; NTH: North Sea). Functions are general to planktivores but parameters are species-specific for herring

\begin{tabular}{|c|c|c|c|}
\hline Eq. & Explanation (units) & Equation & Source \\
\hline (1) & $\begin{array}{l}\text { Feeding rate for multiple prey items } \\
\text { for hour } t \text { of day } d\left(\mathrm{~J} \mathrm{~s}^{-1}\right)\end{array}$ & $i_{t, d}=\sum_{p=1}^{n} \frac{e_{p} P_{c, p} \beta_{p, t, d} N_{p, d}}{1+\sum_{j=1}^{n} h_{j} \beta_{j, t, d} N_{j, d}}$ & Case (2000) \\
\hline (2) & $\begin{array}{l}\text { Search or clearance rate } \\
\left(\mathrm{m}^{3} \mathrm{~s}^{-1}\right)\end{array}$ & $\beta_{p, t, d}=\frac{1}{2} \pi R_{p, t, d}^{2} V(L)$ & \\
\hline (3) & $\begin{array}{l}\text { Length-dependent swimming speed } \\
\left(\mathrm{m} \mathrm{s}^{-1}\right)\end{array}$ & $V(L)=1.5 L$ & $\begin{array}{l}\text { Gibson \& Ezzi (1985), } \\
\text { Pitcher et al. (1985) }\end{array}$ \\
\hline (4) & $\begin{array}{l}\text { Prey detection distance } R(\mathrm{~m}) \text {. The } \\
\text { equation is solved for } R \text { by iteration }\end{array}$ & $R_{p, t, d}^{2} \mathrm{e}^{C_{l o c} R_{t, d}}=\mathrm{C}_{p} A_{p} E(L) \frac{I_{t, d}}{k_{R}+I_{t, d}}$ & Aksnes \& Utne (1997) \\
\hline (5) & $\begin{array}{l}\text { Beam attenuation coefficient } \\
\left(\mathrm{m}^{-1}\right)\end{array}$ & $\begin{array}{l}C_{\mathrm{NWG}}=0.0579+0.363 \mathrm{chl} a^{0.57} \\
C_{\mathrm{NTH}}=0.066+0.3627 \mathrm{chl} a^{0.57}\end{array}$ & $\begin{array}{l}\text { Morel (1991), } \\
\text { Mobley (1994) }\end{array}$ \\
\hline (6) & Prey image area $\left(\mathrm{m}^{3}\right)$ & $A_{p}=0.75 l_{p} d_{p}$ & \\
\hline (7) & $\begin{array}{l}\text { Visual eye sensitivity. This assumes } \\
R \text { is one fish body length for } 4.0 \mathrm{~mm} \\
\text { long prey when light is not limiting } \\
\text { (in clear water, } C_{l o c}=0 \text { ) }\end{array}$ & $E(L)=\frac{L^{2}}{A_{E} C_{p}}$ & Varpe \& Fiksen (2010) \\
\hline (8) & $\begin{array}{l}\text { Ambient irradiance at foraging depth } \\
\left(\mathrm{W} \mathrm{m}^{-2}\right)\end{array}$ & $I_{t, d}=I_{0}(t, d) \mathrm{e}^{-a_{l o c} z}$ & \\
\hline (9) & $\begin{array}{l}\text { Diffuse attenuation coefficient } \\
\left(\mathrm{m}^{-1}\right)\end{array}$ & $\begin{array}{c}a_{\mathrm{NWG}}=0.064+0.0223 \operatorname{chl} a^{0.65} \\
a_{\mathrm{NTH}}=0.125+\operatorname{chl} a\left(0.0506 \mathrm{e}^{-0.606} \operatorname{chl} a+0.0285\right)\end{array}$ & $\begin{array}{l}\text { Voss (1992), } \\
\text { Mobley (1994) }\end{array}$ \\
\hline (10) & $\begin{array}{l}\text { Prey biomass concentration } \\
\left(\mathrm{g} \mathrm{m}^{-3}\right)\end{array}$ & $N_{d, p}=S_{d} N_{\max , p}$ & $\begin{array}{l}\text { See Figs. S1 \& S2 } \\
\text { in Supplement } 1\end{array}$ \\
\hline (11) & Net energy uptake (J) & $\begin{array}{l}U(d)=D_{d}-\left[\left(\alpha_{\mathrm{F}} D_{d}\right)\right. \\
+\alpha_{\mathrm{U}}\left(D_{d}-\left(\alpha_{\mathrm{F}} D_{d}\right)\right) \\
\left.+\alpha_{\mathrm{S}}\left(D_{d}-\left(\alpha_{\mathrm{F}} D_{d}\right)\right)\right]\end{array}$ & \\
\hline$(12)$ & Digested food (J) & $D_{d}=\sum_{t=1}^{24} \min \left[D_{\text {rate }} t, S_{t}\right]$ & \\
\hline (13) & $\begin{array}{l}\text { Digestion rate (or stomach evacuation } \\
\text { rate; } \mathrm{J} \mathrm{h}^{-1} \text { ) }\end{array}$ & $D_{\text {rate }}(t)=\frac{\mathrm{k}_{\mathrm{D}} 44.748 W^{0.7730} \mathrm{e}^{0.0548 T(d)}}{24}$ & $\begin{array}{l}\text { Adapted from } \\
\text { Rudstam (1988) }\end{array}$ \\
\hline (14) & Water temperature $\left({ }^{\circ} \mathrm{C}\right)$ & $\begin{array}{l}T(d)=T_{\mathrm{M}}+T_{\mathrm{A}} z(d) \\
z(d)=\cos \left(d-d_{\text {peak }}\right) \frac{2 \pi}{365}\end{array}$ & \\
\hline (15) & Stomach fullness $(\mathrm{J})$ & $S_{t+1}=\min \left[S_{t}+i_{t, d} S_{\max }\right]-D_{\text {rate }}(t)$ & \\
\hline (16) & Metabolic cost (J) & $M(d)=44.748 W^{0.7730} \mathrm{e}^{0.0548 T(d)}+S(W)$ & $\begin{array}{l}\text { Adapted from } \\
\text { Rudstam (1988) }\end{array}$ \\
\hline (17) & Weight-dependent swimming cost (J) & $S(W)=p_{\mathrm{S}} 44.748 W^{0.7730}$ & \\
\hline
\end{tabular}

Over a wider temperature range, digestion, like many other physiological functions, is a domeshaped function: it increases up to an optimal temperature and then decreases as a result of one or several factors, such as enzyme malfunctioning or reduced oxygen availability (Pörtner 2010). Considering the current range of temperatures at which viable herring populations are found, e.g. in the Baltic Sea where summer temperatures reach about $25^{\circ} \mathrm{C}$, we assume that digestion in Norwegian springspawning (NSS) and North Sea herring at the temperatures that we model $\left(4-14 \pm 2^{\circ} \mathrm{C}\right)$ can be represented by the positive exponential part of a dome-shaped function. 
A full list of all model equations with references is given in Table 1, and the corresponding parameters and variables are given in Table 2. The Fortran source code used for the analyses can be found in Supplement 2 at www.int-res.com/articles/suppl/ m636p001_supp2.pdf.

\subsection{Study systems: comparing 2 herring populations}

The NSS herring is a stock of Atlantic herring that feeds in the Norwegian Sea (see Fig. 2a) during spring and summer (April-September), overwinters in fjords or off the coast of northern Norway (September-January), and then spawns at banks along the Norwegian coast in February and March (Dragesund et al. 1997, Helmuth et al. 2005, Huse et al. 2010). The oldest observed adults reach a body size of about $38.5 \mathrm{~cm}$ (see Fig. 2b), which is the largest for this species. The diet of NSS herring consists primarily of Calanus finmarchicus (ca. $60 \%$ of diet wet weight), euphausiids, and amphipods (Dalpadado et al. 2000, Gislason \& Astthorsson 2002, Dommasnes et al. 2004, Bachiller et al. 2016). Stomach data indicates that
NSS herring stop feeding from the onset of wintering until the termination of spawning activities (Slotte 1999).

In the North Sea, there are 3 herring populations: the northern, central, and southern North Sea herring (Corten 2000, 2001). All 3 populations share the same feeding ground in the northern North Sea where foraging takes place between April and August (see Fig. 2a; Corten 2000, 2001). The central and northern populations spawn in the western North Sea in August and September and overwinter in the region of the Norwegian Trench, whereas the southern population spawns in December-January in the eastern English Channel, and then overwinters in the southern North Sea. North Sea herring are smaller than NSS herring, with a length of the oldest observed adults of about $33 \mathrm{~cm}$ (see Fig. 2b). During the summer season, North Sea herring feed primarily on the calanoid copepods C. finmarchicus and C. helgolandicus as well as post-larval stages of fish (Last 1989). Some feeding appears to also take place outside of the main foraging season, with stomach samples from February containing mainly Calanus, hyperiid amphipods, euphausiids, and fish eggs (Last 1989, Segers et al. 2007). However, few individuals

Table 2. Parameters and variables used in the coupled foraging and bioenergetics model (see Table 1 for equations)

\begin{tabular}{|c|c|c|c|c|}
\hline Symbol & Description & Value & Units & Source \\
\hline$A_{E}$ & Eye-sensitivity coefficient & $4.0 \times 10^{-6}$ & $\mathrm{~m}$ & Varpe \& Fiksen (2010) \\
\hline$\alpha_{F}$ & Egestion coefficient & 0.16 & - & Rudstam (1988) \\
\hline$\alpha_{S}$ & Specific dynamic action coefficient & 0.175 & - & Rudstam (1988) \\
\hline$\alpha_{U}$ & Excretion coefficient & 0.10 & - & Rudstam (1988) \\
\hline chl a & Chlorophyll a concentration & See Table 3 & $\mathrm{mg} \mathrm{m}^{-3}$ & \\
\hline$C_{p}$ & Prey contrast & 0.3 & - & Utne-Palm (1999) \\
\hline$d$ & Day of year & & - & \\
\hline$d_{p}$ & Prey width & & $\mathrm{m}$ & \\
\hline$d_{\text {peak }}$ & Peak day for water temperature & 212 (31 July) & Day of year & van Deurs et al. (2010) \\
\hline$e_{p}$ & Prey energy content & See Table 3 & $\mathrm{~J} \mathrm{~g}^{-1}$ & \\
\hline$h_{p}$ & Prey handling time & See Table 3 & s prey $^{-1}$ & \\
\hline$I_{0}$ & Ambient irradiance at surface & & $\mathrm{W} \mathrm{m} \mathrm{m}^{-2}$ & Bleck (2002) \\
\hline$k_{\mathrm{D}}$ & $\begin{array}{l}\text { Factor calibrating digestion rate to annual } \\
\text { surplus energy approximated from data }\end{array}$ & 10 & - & $\begin{array}{l}\text { Slotte (1999); see Sec- } \\
\text { tion } 1 \text { in Supplement } 1\end{array}$ \\
\hline$k_{\mathrm{R}}$ & Light saturation of $R$ & 1 & $\mu \mathrm{E} \mathrm{m}^{-2} \mathrm{~s}^{-1}$ & Varpe \& Fiksen (2010) \\
\hline$L$ & Fish length & Varied from $10-40 \mathrm{~cm}$ & $\mathrm{~cm}$ & \\
\hline$l_{\mathrm{p}}$ & Prey prosome length & See Table 3 & $\mathrm{~m}$ & \\
\hline$N_{\max , p}$ & Maximum prey abundance & See Table 3 & Prey $\mathrm{m}^{-3}$ & \\
\hline$P_{\mathrm{c}, p}$ & Prey capture success scaling factor & See Table 3 & - & \\
\hline$p_{\mathrm{S}}$ & Proportion of time devoted to swimming & 0.75 (summer); 0.1 (winter) & - & \\
\hline$s_{\mathrm{d}}$ & Seasonal prey abundance scaler & See Supplement 1, Section 3.2 & - & \\
\hline$S_{\max }$ & Maximum gut capacity & $3 \%$ of fish weight & $\mathrm{J}$ & Bernreuther et al. (2008) \\
\hline$t$ & Hour of day & & - & \\
\hline$T_{\mathrm{A}}$ & Temperature amplitude & See Table 3 & ${ }^{\circ} \mathrm{C}$ & \\
\hline$T_{\mathrm{M}}$ & Mean temperature & See Table 3 & ${ }^{\circ} \mathrm{C}$ & \\
\hline$W$ & Fish weight & $W(L)=0.00603 L^{3.0904}$ & g & ICES (2007) \\
\hline$z$ & Foraging depth & See Table 3 & $\mathrm{~m}$ & \\
\hline
\end{tabular}


have food in their stomachs, and low stomach contents suggest that feeding during this period is limited (Daan et al. 1985, Last 1989). Parameter values and references for prey characteristics are given in Table S1 in Supplement 1.

The Norwegian Sea and the North Sea differ in several aspects known to influence foraging rates and bioenergetics of planktivores: (1) located at a higher latitude, the Norwegian Sea has more daylight hours in spring and summer; (2) in summer, the North Sea is considerably warmer than the Norwegian Sea while winter temperatures are similar; (3) the North Sea has lower water clarity and hence less light can penetrate the water column; (4) the zooplankton communities in the 2 seas are quite different: total biomass is higher in the Norwegian Sea $(9.2$ vs. $5.7 \mathrm{~g}$ dry weight $\mathrm{m}^{-2}$; Norwegian Sea: 1995-2015, Broms 2016; North Sea: 2005-2014, Falkenhaug 2016), and the deeper Norwegian Sea mainly contains zooplankton of larger size, while the shallower North Sea is characterized by smaller sized zooplankton (Melle et al. 2004, Pitois et al. 2009). In spring, C. finmarchicus are advected into the northern North Sea where they mix with C. helgolandicus (Fransz et al. 1991). There is no discernible difference in size or energy content between C. finmarchicus and C. helgolandicus in the North Sea (Wilson et al. 2015), but C. finmarchicus are typically larger at higher latitudes (Boxshall \& Schminke 1988, Skjoldal 2004, Jónasdóttir et al. 2005, Jonasdottir \& Koski 2011).

We collected environmental drivers for the Norwegian and North Sea systems from the literature: seasonal water temperatures (Slotte \& Fiksen 2000, van Deurs et al. 2010); seasonal and diurnal cycles in surface solar irradiance as a function of latitude (Bleck 2002); water clarity (based on chl a concentrations; Norwegian Sea, Huse \& Fiksen 2010; North Sea, van Deurs et al. 2015); seasonal prey biomass distributions (North Sea, Colebrook 1979; Norwegian Sea, Varpe \& Fiksen 2010); and zooplankton biomass and size fractions (Broms 2016, Falkenhaug 2016). Length- and weight-at-age data for NSS and North Sea herring were obtained from scientific surveys conducted by the Institute of Marine Research, Bergen, Norway. Samples from $60^{\circ} \mathrm{N}$ upwards are categorized as NSS herring, while data below this latitude are North Sea herring. We used data for the years 1995-2005 as this represents a period of relatively stable stock dynamics for both stocks. Especially for the younger age classes, fish of the same age can have very different lengths depending on the time of the year they have been sampled. To reduce this bias, we used individuals sampled between January and June, as this is also the period where most of the data was sampled. In total, we used 253105 individuals for NSS herring and 141624 individuals for North Sea herring.

\subsection{Analyses}

\subsubsection{Predicting optimal body size in 2 herring populations}

The Norwegian Sea and the North Sea differ in several aspects known to influence foraging rates and bioenergetics. Can these environmental factors explain the difference in body size observed between herring in these 2 seas? To answer this question, we ran the model with environmental drivers representative of each system (default scenarios; Table 3, 'Case study') and with interannual variation in annual water temperature (default $\pm 2^{\circ} \mathrm{C}$ ), prey biomass concentration (default $\pm 20 \%$ ), and chl a concentration (default $\pm 20 \%$ ) typical in these systems. We assumed the diet of NSS herring to consist of $60 \%$ C. finmarchicus and $40 \%$ euphausiids and amphipods, as this is the approximate wet weight ratio observed in stomach content data from summer samples (Dalpadado et al. 2000, Gislason \& Astthorsson 2002, Dommasnes et al. 2004, Bachiller et al. 2016). To simplify interpretation of the results, as well as to account for some feeding outside of the main foraging season in North Sea herring, we assumed a wet weight ratio in the diet of North Sea herring of $60 \%$ C. finmarchicus and C. helgolandicus, and $40 \%$ larger prey (Last 1989). See Section 2 in Supplement 1 for details about the diets of the 2 herring populations, Section 3 in Supplement 1 for values and references used to parameterize prey characteristics, and Section 4.1.1 in Supplement 1 for assumptions and calculations relating to prey biomass fractions.

\subsubsection{Drivers of optimal body size in NSS and North Sea herring}

Why does body size in the spatially adjacent NSS and North Sea herring populations differ? We explored this by running a sensitivity analysis of our results from the 'Case study' (default scenarios) by systematically changing prey characteristics (prosome length, energy content, and biomass concentration) and the physical environment (latitude, 
Table 3. Parameter values used in the case study and sensitivity analysis of Norwegian spring-spawning herring and North Sea herring and in the detailed analysis

\begin{tabular}{|c|c|c|c|}
\hline \multirow[t]{2}{*}{ Parameter } & \multirow[t]{2}{*}{ General analysis } & \multicolumn{2}{|c|}{ Case study (sensitivity analysis) } \\
\hline & & North Sea & Norwegian Sea \\
\hline \multicolumn{4}{|c|}{ Prey characteristics (in case study specified for prey type: 1 , small; 2 , large) } \\
\hline Prosome length (mm) & $2,3,4$ & $2.6,14.4( \pm 20 \%)$ & $3.0,14.4( \pm 20 \%)$ \\
\hline Energy content $\left(\mathrm{J} \mathrm{g}^{-1}\right)$ & $\begin{array}{c}2.72 \times 10^{3}, 3.26 \times 10^{3} \\
3.81 \times 10^{3}\end{array}$ & $\begin{array}{c}3.48 \times 10^{3}, 2.83 \times 10^{3} \\
( \pm 20 \%)\end{array}$ & $\begin{array}{c}3.26 \times 10^{3}, 2.83 \times 10^{3} \\
( \pm 20 \%)\end{array}$ \\
\hline $\begin{array}{l}\text { Max. biomass concentration } \\
\left(\mathrm{g} \mathrm{m}^{-3}\right)\end{array}$ & $0.35,0.70,1.05$ & $\begin{array}{c}0.39,0.12( \pm 20 \%) \text { (see } \\
\text { Supplement } 1 \text {, Section } \\
4.1 .1 \text { for calculations) }\end{array}$ & $\begin{array}{c}0.70,0.18( \pm 20 \%) \text { (see } \\
\text { Supplement } 1, \text { Section } \\
4.1 .1 \text { for calculations) }\end{array}$ \\
\hline Foraging depth (m) & 30 & 20,20 & 30,60 \\
\hline \multicolumn{4}{|l|}{ Physical environment } \\
\hline \multirow[t]{3}{*}{ Water temperature $\left({ }^{\circ} \mathrm{C}\right)$} & $\begin{array}{l}3.5,5.5,7.5 \\
1.5,1.5,1.5\end{array}$ & $\begin{array}{c}\text { Annual warming } \\
7,9,11 \\
5,5,5\end{array}$ & $\begin{array}{c}\text { Annual warming } \\
3.5,5.5,7.5 \\
1.5,1.5,1.5\end{array}$ \\
\hline & & $\begin{array}{c}\text { Summer warming } \\
8,9,10 \\
4,5,6\end{array}$ & $\begin{array}{c}\text { Summer warming } \\
4.5,5.5,6.5 \\
0.5,1.5,2.5\end{array}$ \\
\hline & & $\begin{array}{l}\text { Winter warming } \\
\begin{array}{c}8,9,10 \\
6,5,4\end{array}\end{array}$ & $\begin{array}{l}\text { Winter warming } \\
\begin{array}{l}4.5,5.5,6.5 \\
2.5,1.5,0.5\end{array}\end{array}$ \\
\hline Chlorophyll a concentration $\left(\mathrm{mg} \mathrm{m}^{-3}\right)$ & $0,1,2$ & $2 \pm 20 \%$ & $1 \pm 20 \%$ \\
\hline \multicolumn{4}{|l|}{ Other parameters } \\
\hline Handling time $\left(\right.$ s prey $\left.^{-1}\right)$ & 1.5 & $1.5,5( \pm 1 \mathrm{~s})$ & $1.5,5( \pm 1 \mathrm{~s})$ \\
\hline Capture success scaling factor & 0.3 & $0.5,0.3( \pm 10 \%)$ & $0.3,0.1( \pm 10 \%)$ \\
\hline
\end{tabular}

water clarity, water temperature: annual, summer, and winter) (Table 3, 'Sensitivity analysis'). Importantly, to be able to assess the influence of prey size on optimal size, we assumed a constant prey biomass concentration $\left(\mathrm{g} \mathrm{m}^{-3}\right)$ and scaled prey concentration (prey $\mathrm{m}^{-3}$ ) according to prey size (see Section 4.1.2 in Supplement 1 for calculations). We also checked the sensitivity of the model to 2 other parameters that could have potentially large effects on feeding rate: prey handling time and capture success (accounting for feeding constraints imposed by capture efficiency, overlapping search fields, schooling behavior, different habitats of prey, etc.).

\subsubsection{Drivers of optimal body size in planktivores}

To investigate the effect of each of the environmental drivers on foraging rates and bioenergetics in more detail, we used parameter values typical for the Norwegian Sea and NSS herring as a default scenario and specified general but realistic ranges for the parameters used to describe prey characteristics and the physical environment. We then checked the sensitivity of the predicted default optimal size to variations in each of these parameters, while keeping the other parameters constant (see 'General analysis' in Table 3 for parameter values tested and Section 4.1.3 in Supplement 1 for calculations of prey-sizespecific prey concentrations).

\section{RESULTS}

\subsection{Optimal size in NSS and North Sea herring}

We define optimal body size as the size at which surplus energy is maximized, and hence being smaller or larger would imply less energy available for reproduction and other fitness-related tasks. Since herring display indeterminate growth and are unlikely to live until they die of old age, the oldest individuals in these populations should be the ones that display body sizes close to our predicted value (represented by the dark purple, blue, and grey colors in Fig. 2b). The optimal lengths predicted by our 

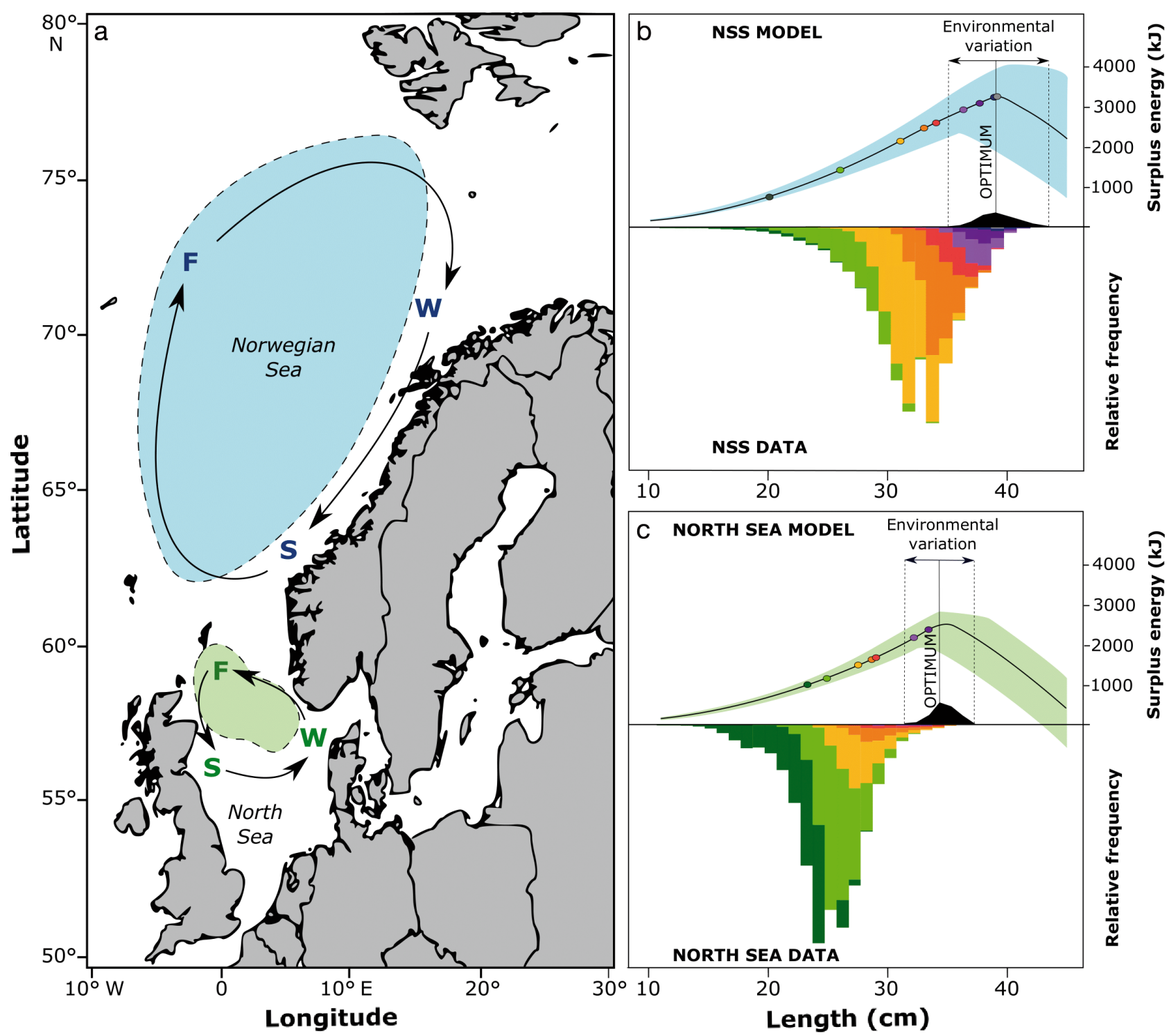

Fig. 2. (a) Annual migration patterns of Norwegian spring spawning herring (NSS; top) and North Sea herring (bottom) showing F: feeding; W: overwintering; and S: spawning areas. Feeding areas of NSS herring and North Sea herring are highlighted in blue and green, respectively. For the North Sea, the northern and central components are shown; the southern stock spawns and overwinters further south. Distribution of real body lengths (DATA) and predicted optimal lengths (MODEL) under environmental variation (annual water temperature, default $\pm 2{ }^{\circ} \mathrm{C}$; prey abundance, default $\pm 20 \%$; chl a concentration, default $\pm 20 \%$ ) for (b) NSS herring, and (c) North Sea herring. Colors from dark green to grey refer to cohorts aged 3-4, 5-6, 7-8, 9-10, 11-12,13-14, 15-16, and 17+ yr. Data plots show frequency of each cohort relative to the total number of individuals; colored circles: mode of each cohort group

model, from typical values in water temperature, prey biomass concentration, and water clarity, corresponded well with observations for NSS (39 vs. $38.5 \mathrm{~cm}$; Fig. 2 b) and North Sea herring ( 34 vs. 33 cm; Fig. 2c), suggesting that the model captures the main drivers of herring body size in these systems. Optimal length was predicted to be smaller for North Sea herring than NSS herring ( $34 \mathrm{vs.} 39 \mathrm{~cm}$ ), which is also in line with observations (Fig. 2b,c). For both stocks, energy intake in smaller and medium sized fish is primarily limited by digestion, while prey encounters is the main limiting factor for larger individuals (Fig. 3). The deviation between the dotted line (showing the maximum amount of food that can be digested in a year) and the solid line (showing actual digested food) visible in the top panel of Fig. 3 results from encounter limitation for some hours of some days of the feeding season (see Eq. 12 in Table 1). 

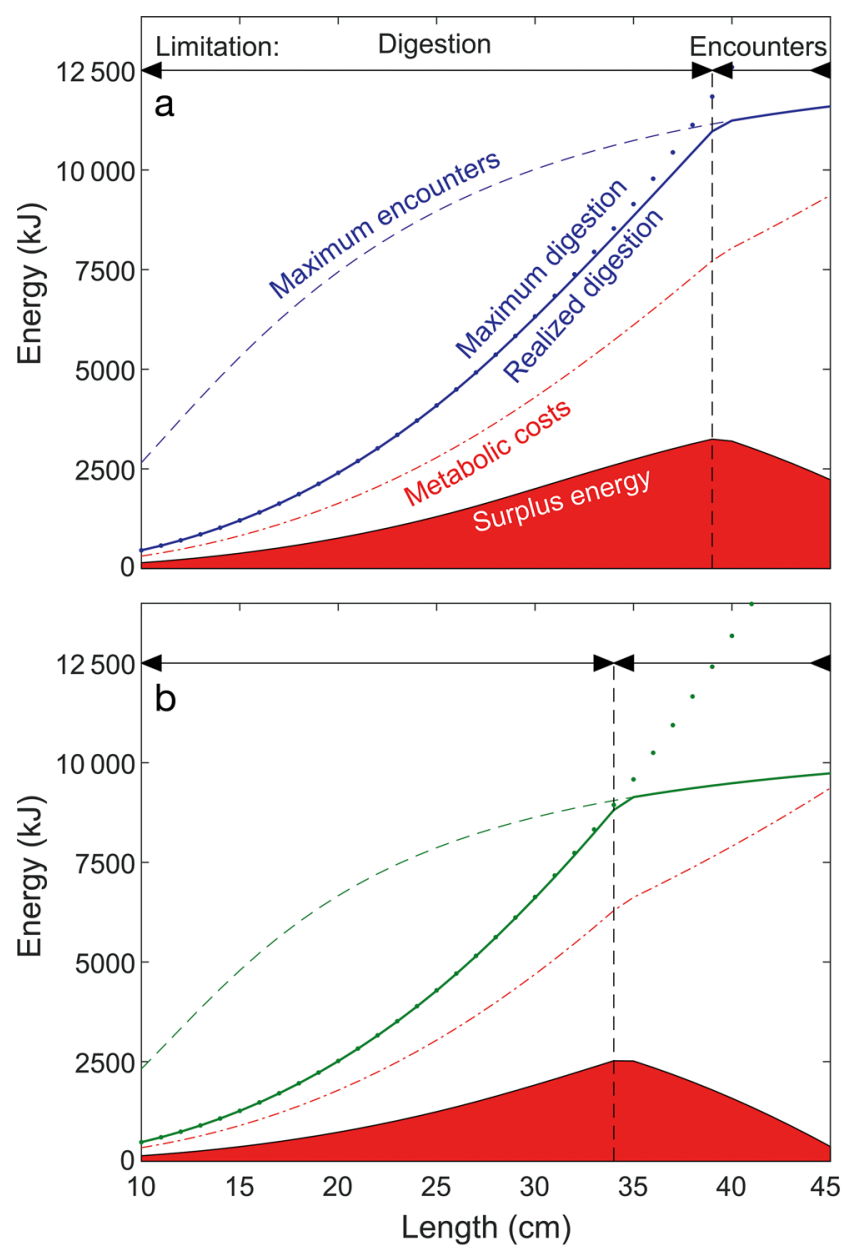

Fig. 3. Predictions for (a) NSS herring and (b) North Sea herring default scenarios. Solid lines: digested food (depends on stomach content; $\mathrm{kJ} \mathrm{yr}^{-1}$ ); dotted lines: maximum amount of food that can be digested (independent of stomach content; $\left.\mathrm{kJ} \mathrm{yr}^{-1}\right)$; dashed blue and green lines: maximum potential food intake when there is no digestion limitation (sum of feeding rate; $\left.\mathrm{kJ} \mathrm{yr}^{-1}\right)$; red dotdash lines: metabolic cost $(\mathrm{kJ}$ $\mathrm{yr}^{-1}$ ). Red areas: difference between digested food and metabolic cost, thus representing annual surplus energy $(\mathrm{kJ})$ of herring in (a) the Norwegian Sea and (b) the North Sea. Dashed vertical lines: predicted optimal size. 'Limitations' indicates lengths at which digestion and prey encounters, respectively, limit energy acquisition

\subsection{What drives the difference in body size in NSS and North Sea herring?}

Prey size was the most influential factor on optimal size in both NSS and North Sea herring: larger prey increased optimal herring size and surplus energy, even if the total prey biomass concentration was held constant (Fig. 4). Prey energy content also had a large effect on optimal size, while that of prey biomass concentration was only minor. Like- wise, applying the seasonal prey biomass curve of the North Sea to the Norwegian Sea scenario and vice versa had no effect on the optimal size of NSS herring, and gave a slightly smaller optimal size for North Sea herring (see Fig. S3 in Supplement 1). Since energy content and handling time was the same for both systems, this suggests that the smaller optimal size predicted for North Sea herring results from their slightly smaller and thus less visible prey.

Higher temperature reduced optimal size, whereas more light (higher latitude, clearer water) gave larger optimal size (Fig. 4). Is it possible that a higher metabolic cost in the warmer North Sea leads to less surplus energy and hence a smaller optimal size? Our results do not suggest so, since the difference in annual metabolic cost between the 2 systems is marginal (Fig. 3). Furthermore, for both stocks, optimal size was very sensitive to variation in capture success and handling time of the smaller prey item, with lower capture success and longer handling times leading to smaller optimal size (Fig. 4).

\subsection{What drives optimal body size in planktivores?}

All the environmental drivers included in our model except temperature affect feeding rates, which is illustrated by the difference in the asymptotes of the dashed lines in Fig. 5, showing maximum potential food intake when there is no digestion limitation. Under constant rates of digestion and metabolism (constant temperature), higher feeding rates thus lead to larger optimal size. Prey size had the most dominant effect on feeding rate, with a difference in prey length of $1 \mathrm{~mm}$ leading to an average difference in optimal length of more than $10 \mathrm{~cm}$. The second most influential prey parameter was energy content, while the effect of variation in prey biomass concentration was negligible. More daylight hours at higher latitudes increased feeding opportunities, and variation in water clarity had a strong effect. Higher temperature was associated with smaller optimal size but with approximately the same amount of surplus energy. This was due to faster digestion, which alleviates digestion limitation at smaller sizes and thus allows for a greater energy uptake. This is in line with the temperature-size rule. However, contrary to the intuitive result of a more constrained energy budget with higher temperature, our model shows that such a relationship may arise even with a conserved energy budget. 


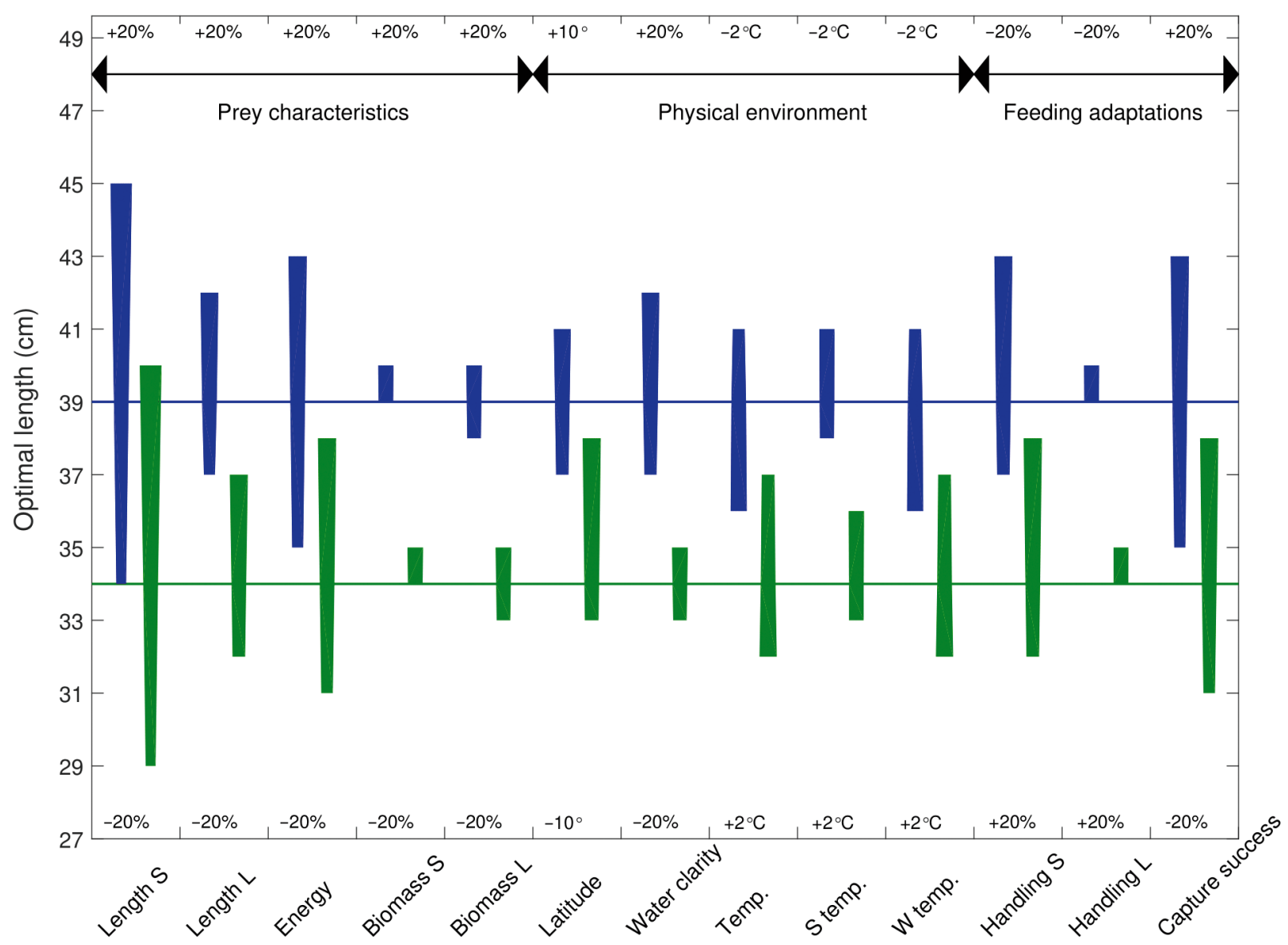

Fig. 4. Sensitivity of herring optimal length and surplus energy at optimal length to variation in prey characteristics, the physical environment, and feeding adaptations. Horizontal blue and green lines: predicted optimal lengths for NSS herring and North Sea herring, respectively, for parameter values representing their natural environment (default). The values along the $x$ - and $y$-axis correspond to the end points of the bars; bar thickness represents amount of surplus energy in proportion to the default scenario. For parameters length, biomass concentration, and handling time, sensitivity to variation in the smaller

(S) and larger (L) prey item is shown

\section{DISCUSSION}

\subsection{Environmental drivers of optimal body size in planktivores}

\subsubsection{Prey characteristics}

Our main finding was that prey size appears to be a dominant driver of body size variation, by affecting prey detection distance and therefore encounter rates. Prey energy content also had a major influence through its effect on the relative profitability of different prey types. A similar model for lesser sandeel Ammodytes marinus in the North Sea showed corresponding results: the potential growth rate was roughly halved when large, energy-rich Calanus were replaced by smaller copepods (van Deurs et al. 2015). The importance of resources for geographic variation in body size has been highlighted before (discussed in McNab 2010, Watt et al. 2010, Teplitsky \& Millien 2014, Vinarski 2014), but the focus has generally been on the effects of food abundance and spatio-temporal availability. Similarly, ecosystem models that include multiple predator-prey interactions commonly base consumption estimates solely on prey biomass concentration. In our model, biomass concentration was the least essential prey characteristic for feeding rates. We therefore suggest that models of consumption should consider all prey traits that are important for visual feeding rates, as well as factors that restrict feeding (see Sections 4.1.2 and 4.1.3 below). Prey biomass should not be ignored, but it may impact survival more than growth (Fiksen \& Jørgensen 2011), and hence the relationships between prey abundance, consumption rates, and predator biomass assumed in many ecosystem models are not necessarily linear. 

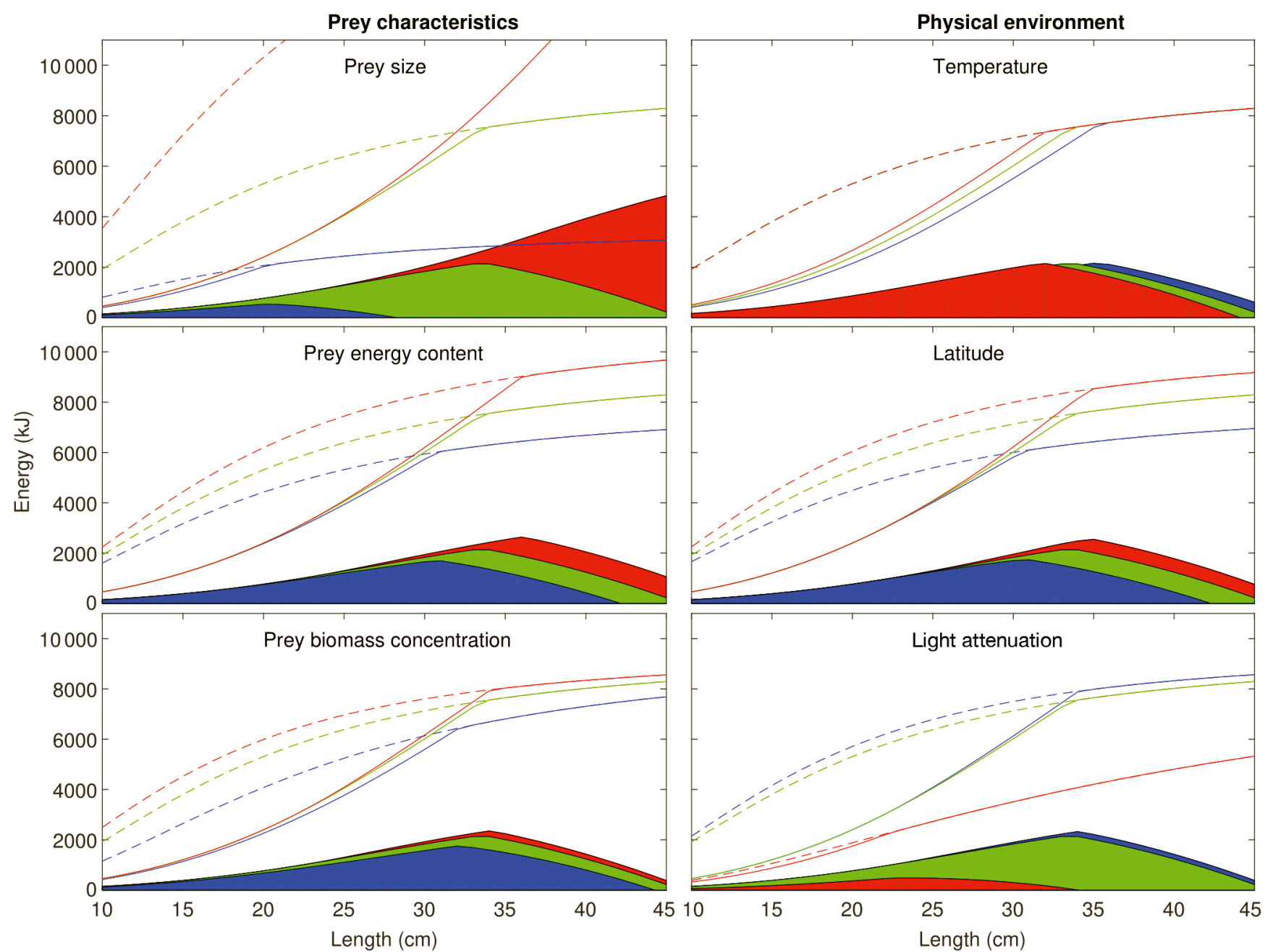

Fig. 5. Sensitivity of herring optimal length to variation in prey characteristics and the physical environment. Solid lines: digested food $\left(\mathrm{kJ} \mathrm{yr}^{-1}\right)$; dashed lines: maximum potential food intake when there is no digestion limitation (sum of feeding rate;

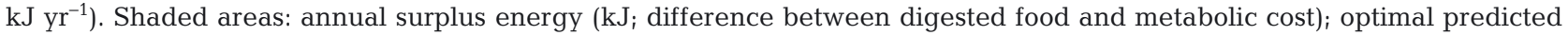
length can be read from their maximum values. Green: default scenario (middle value); blue and red: lower and higher values of the parameter, respectively: prey size $(2,3,4 \mathrm{~mm})$, prey energy content $\left(2.72 \times 10^{3}, 3.26 \times 10^{3}, 3.81 \times 10^{3} \mathrm{~J} \mathrm{~g}^{-1}\right)$, prey biomass concentration $\left(0.35,0.70,1.05 \mathrm{~g} \mathrm{~m}^{-3}\right)$, mean water temperature $\left(3.5,5.5,7.5^{\circ} \mathrm{C}\right)$, latitude $\left(58,68,78^{\circ} \mathrm{N}\right)$, and light attenuation (high light attenuation = low water clarity; 0, 1,2 $\mathrm{mg} \mathrm{chl} \mathrm{a} \mathrm{m}^{-3}$ )

\subsubsection{Feeding adaptations: prey handling time and capture success}

In addition to prey size and energy content, our model predictions were sensitive to variation in prey handling time and capture success. Thus, if possible, individuals would benefit from being more efficient predators. In the model, these 2 parameters are assumed to encompass several factors that limit feeding rate, including prey shape, evasiveness, anti-predator behaviors and mobility. Handling time and capture success are outcomes of eons of natural selection that has optimized the feeding machinery in trade-offs with other traits.
The potential for evolution toward higher efficiency is thus presumably low. Our findings suggest that the accuracy with which handling time and capture success are parameterized is crucial for realistic estimates. Hence, research should be devoted to investigating the actual values of these parameters for different predators and prey, and under varying environmental conditions.

\subsubsection{Light}

Visual prey detection is not only affected by prey size, but also by light (Aksnes \& Utne 1997). More 
hours of light allow for more time feeding and prey are easier to detect in clearer water, yielding higher prey consumption and therefore larger optimal size. This suggests that longer days in spring and summer at higher latitudes contribute to a latitudinal size cline in visually foraging planktivores that acquire most of their energy during this period. Similarly, longer days in spring are a main driver of the rapid increase in body condition observed in NSS herring from spring to mid-summer, while prey phenology and abundance are less important (Varpe \& Fiksen 2010).

Our results also suggest that clearer water facilitates growth to a larger size in visual planktivores, and more so at low than high latitudes, as long as food uptake is not constrained by digestive capacity. Correspondingly, low water clarity has a negative impact on feeding rates in several planktivorous fish (e.g. bluegill Lepomis macrochirus, Vinyard \& O'Brien 1976; trout Salvelinus fontinalis, Confer et al. 1978; goby Gobiusculus flavescens Utne 1997; three-spined stickleback Gasterosteus aculeatus, Helenius et al. 2013; damselfish Pomacentridae, Johansen \& Jones 2013). The general importance of light-related constraints for foraging is well known from both experimental (Vinyard \& O'Brien 1976, Utne 1997, Sørnes \& Aksnes 2004) and modeling studies (Eggers 1977, Aksnes \& Utne 1997, Langbehn \& Varpe 2017). Nonetheless, one may claim its broader ecological effects are underappreciated and reiterated emphasis thus needed (e.g. see Varpe et al. 2015, Langbehn \& Varpe 2017, Langbehn et al. 2019).

\subsubsection{Temperature}

In agreement with the generally expected effect of temperature on body size, our model predicts smaller optimal sizes at higher water temperatures. The mechanism responsible for this pattern is, however, different from those previously proposed. In contrast to a consequence of temperature effects on growth and maturation (Atkinson 1994, Angilletta \& Dunham 2003, Audzijonyte et al. 2019) or on metabolic rate (Sheridan \& Bickford 2011), a smaller predicted optimal size at higher temperature was due to faster digestion, leading to prey encounter limitation at a smaller size. The level of surplus energy did not change with temperature. Thus, even though a decrease in size due to warmer temperatures may be disadvantageous from a size-based predation-risk perspective (size-dependent mortality; Peterson \&
Wroblewski 1984), conserved energy reserves could imply unchanged foraging-related predation and reproductive potential. These findings are relevant for a $2^{\circ} \mathrm{C}$ warming, which is within the range of temperatures at which herring currently do well. However, since many physiological functions break down or are impeded above an optimum temperature, several degrees of warming would likely lead to different results.

\subsection{Different optimal size in NSS and North Sea herring}

Our model predictions of optimal body size for herring in the Norwegian Sea and the North Sea correspond well with field observations of the sizes of the oldest individuals of herring in these 2 seas (39 vs. $38.5 \mathrm{~cm}$ for NSS and $34 \mathrm{vs.} 33 \mathrm{~cm}$ for North Sea herring). This indicates that our model captured the main drivers of body size and hence that the physical environments of the Norwegian Sea and the North Sea (water temperature, hours of daylight, and water clarity) are not likely to be responsible for the observed difference in body size between NSS and North Sea herring. Rather, the likely cause is the smaller prey in the diet of North Sea herring, imposing visual constraints and thus prey encounter limitation at a smaller size. The close match between our predictions and observations also indicates that energetics rather than predation risk and intra-specific interactions determines body size in these systems. This assumption is not unrealistic since energetic constraints generally have a large influence on lifehistory strategies in environments where resources are seasonal (Boyce 1979, Roff 1992, Stearns 1992, Varpe 2017, Ljungström et al. 2019).

In this study, we modeled optimal body size. Thus, the good fit between our predictions and observations also suggests that NSS and North Sea herring differ in size because of local adaptation or evolved phenotypic plasticity to the local prey field. The prey field of herring in the Norwegian Sea is more homogeneous and less variable than in the North Sea, where it contains many species that vary in relative abundance on a seasonal and inter-annual scale (Beaugrand et al. 2002). Based on our predictions, this suggests that the large size of NSS herring is due to local adaptation, but that both populations may be expected to display variable body sizes through adaptive phenotypic plasticity to variable environmental conditions (Kawecki \& Ebert 2004, Ghalambor et al. 2007). 


\subsection{Adaptive body size shifts under climate change}

Reductions in body size have been proposed as the third universal response to climate change (Daufresne et al. 2009, Gardner et al. 2011, Sheridan \& Bickford 2011) and have been linked to negative population level effects, including declines in biomass and fecundity and increased mortality rates (Cheung et al. 2011, 2013, Baudron et al. 2014, Waples \& Audzijonyte 2016). In our analyses, smaller optimal sizes at warmer temperatures were not associated with lower levels of surplus energy, indicating that negative effects on productivity are not necessarily universal. Moreover, for planktivores that forage through vision, our findings suggest that an altered prey field composition could have a greater impact on body size, and on the energy available for reproduction and other fitness-related tasks, than warming-driven changes in digestion and metabolic rate. This is likely to be a plausible prediction for many species within this group, which are highly specialized for feeding on small zooplankton prey.

Primary production in the marine realm is forecasted to undergo large-scale changes in timing, distribution, and intensity (e.g. Sarmiento et al. 2004, Steinacher et al. 2010, Chavez et al. 2011, Chust et al. 2014), and recent shifts in zooplankton community composition have been associated with warmer waters and altered water flows (Richardson \& Schoeman 2004, Behrenfeld et al. 2006, Beaugrand et al. 2009). A subsequent change in optimal body size, and hence the size at which fitness is maximized, could have several possible outcomes for a local population. A population that is adapted to a fairly homogeneous and stable prey environment, such as NSS herring, would only maintain its fitness by tracking a prey field that is of similar quality. In contrast, a population that is adapted to a more heterogeneous and temporally fluctuating prey field, such as North Sea herring, may have better prospects to stay and cope with the new conditions. As a consequence, the most pronounced body size shifts in response to changes in the local prey field may be expected in species that depend on specific physical characteristics of their habitat, thus making dispersal or range shifts difficult. As an example, the lesser sandeel in the North Sea is behaviorally attached to its sandy bottom habitat, and the average body size in this population has been decreasing since the late 1980s in parallel with a switch in the local prey field from their preferred prey Calanus finmarchicus to smaller prey items (van Deurs et al. 2015).

Apart from changes in temperature and prey quality, our model predicts that altered water clarity influ- ences body size in visually foraging planktivores. We modeled water clarity as a function of primary production (chl a concentration), but this variable is also affected by dissolved organic matter and particle load (Kirk 2011). These 2 factors are mainly influenced by terrestrial runoff and thus rainfall and wind patterns, which are also projected to be altered by climate change (Kirtman et al. 2013). Thus, populations in regions with e.g. increased primary production or stronger winds, or in coastal regions with increased freshwater runoff, could also experience selection for smaller body size. The importance of accounting for changes in the light regime in analyses of marine ecosystem change has been highlighted before (Aksnes 2007, Varpe \& Fiksen 2010, Varpe et al. 2015, Langbehn \& Varpe 2017), but to our knowledge, not in relation to body-size shifts in visual planktivores under climate change.

Lastly, our findings also have implications for the prediction of range shifts under climate change. Range shifts in marine species have predominantly been predicted based on projections by bioclimate envelope models (e.g. Cheung et al. 2009, Jones \& Cheung 2015, García Molinos et al. 2016), which use statistical relationships between current species' distributions and their physical environments to project where a species should be present in the future. For marine species, the most commonly used predictor is temperature, but salinity, depth, and habitat type are also typically included to determine habitat suitability (e.g. Cheung et al. 2009, Hare et al. 2010, Cheung et al. 2011, also oxygen content and acidity; García Molinos et al. 2016). The underlying assumption of these models is thus that species will track preferred physical conditions (Guisan \& Zimmermann 2000, Elith \& Leathwick 2009) and they have been criticized for not considering how species interactions shape their distributions (see e.g. Pearson \& Dawson 2003, Dormann et al. 2012, Thuiller et al. 2013, Urban et al. 2016). By suggesting that prey accessibility (mediated by prey characteristics and light availability) is more important for the energy budget of visual aquatic foragers than temperature, the findings of this study highlight the importance of understanding mechanistic links between interacting species in order to predict their future ranges.

\section{CONCLUDING REMARKS}

Spatial and temporal variation in temperature may be a primary global driver of latitudinal clines and recent reductions in body size. However, here 
we have shown that prey characteristics are the most influential determinant for optimal body size in a planktivorous fish, imposing visual constraints on prey encounters and thereby limiting feeding rates. In the oceans, planktivores determine the flux of energy from lower to higher trophic levels. Thus, to accurately predict the consequences of environmental change for energy flows and body sizes in marine systems, there is a need to consider all factors that affect energy budgeting in this group of organisms.

Acknowledgements. The authors received funding through the MARmaED project from the European Union's Horizon 2020 research and innovation programme under the Marie Skłodowska-Curie grant agreement no. 675997. The results of this publication reflect only the authors' view, and the Commission is not responsible for any use that may be made of the information it contains. We thank Loïc Baulier for discussions on the topic. G.L. thanks Cecilie Broms for providing zooplankton data for the Norwegian Sea, and for explaining the details of zooplankton sampling. C.J. acknowledges funding from Research Council of Norway, project no. 294819.

\section{LITERATURE CITED}

Aksnes DL (2007) Evidence for visual constraints in large marine fish stocks. Limnol Oceanogr 52:198-203

Aksnes D, Utne ACW (1997) A revised model of visual range in fish. Sarsia 4827:37-41

Alder J, Campbell B, Karpouzi V, Kaschner K, Pauly D (2008) Forage fish: from ecosystems to markets. Annu Rev Environ Resour 33:153-166

Angilletta MJ Jr, Dunham AE (2003) The temperature size rule in ectotherms: simple evolutionary explanations may not be general. Am Nat 162:332-342

* Angilletta MJ Jr, Steury TD, Sears MW (2004) Temperature, growth rate, and body size in ectotherms: fitting pieces of a life-history puzzle. Integr Comp Biol 44:498-509

Atkinson D (1994) Temperature and organism size-A biological law for ectotherms? In: Begon M, Fitter AH (eds) Advances in ecological research, Vol 25. Academic Press, London, p 1-58

Atkinson D, Morley SA, Hughes RN (2006) From cells to colonies: At what levels of body organization does the 'temperature-size rule' apply? Evol Dev 8:202-214

Audzijonyte A, Kuparinen A, Fulton EA (2013) How fast is fisheries-induced evolution? Quantitative analysis of modelling and empirical studies. Evol Appl 6:585-595

* Audzijonyte A, Belmaker J, Barneche DR, Baudron AR and others (2019) Is oxygen limitation in warming waters a valid mechanism to explain decreased body sizes in aquatic ectotherms? Glob Ecol Biogeogr 28:64-77

Bachiller E, Skaret G, Nøttestad L, Slotte A (2016) Feeding ecology of Northeast Atlantic mackerel, Norwegian spring-spawning herring and blue whiting in the Norwegian Sea. PLOS ONE 11:e0149238

Baudron AR, Needle CL, Marshall CT (2011) Implications of a warming North Sea for the growth of haddock Melanogrammus aeglefinus. J Fish Biol 78:1874-1889
Baudron AR, Needle CL, Rijnsdorp AD, Tara Marshall C (2014) Warming temperatures and smaller body sizes: synchronous changes in growth of North Sea fishes. Glob Change Biol 20:1023-1031

*Beaugrand G, Ibañez F, Lindley JA, Reid PC (2002) Diversity of calanoid copepods in the North Atlantic and adjacent seas: species associations and biogeography. Mar Ecol Prog Ser 232:179-195

* Beaugrand G, Luczak C, Edwards M (2009) Rapid biogeographical plankton shifts in the North Atlantic Ocean. Glob Change Biol 15:1790-1803

* Behrenfeld MJ, O'Malley RT, Siegel DA, McClain CR and others (2006) Climate-driven trends in contemporary ocean productivity. Nature 444:752-755

Bergmann C (1847) Ueber die Verhältnisse der Wärmeökonomie der Thiere zu ihrer Grösse. Göttinger Studien 3: 595-708

Bernreuther M, Herrmann JP, Temming A (2008) Laboratory experiments on the gastric evacuation of juvenile herring (Clupea harengus L.). J Exp Mar Biol Ecol 363:1-11

*Backburn TM, Gaston KJ, Loder N (1999) Geographic gradients in body size: a clarification of Bergmann's rule. Divers Distrib 5:165-174

Bleck R (2002) An oceanic general circulation model framed in hybrid isopycnic-Cartesian coordinates. Ocean Model 4:55-88

Boxshall GA, Schminke HK (eds) (1988) Biology of copepods: proceedings of the third international conference on Copepoda. Kluwer Academic Publishers, Dordrecht

Boyce MS (1979) Seasonality and patterns of natural selection for life histories. Am Nat 114:569-583

* Brander K, Neuheimer A, Andersen KH, Hartvig M (2013) Overconfidence in model projections. ICES J Mar Sci 70: 1065-1068

Broms C (2016) Dyreplankton i Norskehavet. In: Havforskningsrapporten 2016. Institute of Marine Research, Bergen, p 98-99

Case TJ (2000) An illustrated guide to theoretical ecology. Oxford University Press, New York, NY

* Caves E, Sutton T, Johnsen S (2017) Visual acuity in rayfinned fishes correlates with eye size and habitat. J Exp Biol 220:1586-159

Charlesworth B (1994) Evolution in age-structured populations, $2^{\text {nd }}$ edn. Cambridge University Press, Cambridge

* Chavez FP, Messié M, Pennington JT (2011) Marine primary production in relation to climate variability and change. Annu Rev Mar Sci 3:227-260

Cheung WWL, Lam VWY, Sarmiento JL, Kearney K, Watson R, Pauly D (2009) Projecting global marine biodiversity impacts under climate change scenarios. Fish Fish 10: 235-251

Cheung WWL, Dunne J, Sarmiento JL, Pauly D (2011) Integrating ecophysiology and plankton dynamics into projected maximum fisheries catch potential under climate change in the Northeast Atlantic. ICES J Mar Sci 68: 1008-1018

* Cheung WWL, Sarmiento JL, Dunne J, Frölicher TL and others (2013) Shrinking of fishes exacerbates impacts of global ocean changes on marine ecosystems. Nat Clim Chang 3:254-258

* Chust G, Allen JI, Bopp L, Schrum C and others (2014) Biomass changes and trophic amplification of plankton in a warmer ocean. Glob Change Biol 20:2124-2139

* Colebrook JM (1979) Continuous plankton records: seasonal cycles of phytoplankton and copepods in the 
northeastern North Atlantic and the North Sea. Mar Biol 51:23-32

Confer JL, Howick GL, Corzette MH, Kramer SL, Fitzgibbon S, Landesberg R (1978) Visual predation by planktivores. Oikos 31:27-37

Corten A (2000) A possible adaptation of herring feeding migrations to a change in timing of the Calanus finmarchicus season in the eastern North Sea. ICES J Mar Sci 57:1261-1270

Corten A (2001) Northern distribution of North Sea herring as a response to high water temperatures and/or low food abundance. Fish Res 50:189-204

* Cushman JH, Lawton JH, Manly BFJ (1993) Latitudinal patterns in Europe ant assemblages: variation in species richness and body size. Oecologia 95:30-37

Daan N, Rijnsdorp AD, Van Overbeeke GR (1985) Predation by North Sea herring Clupea harengus on eggs of plaice Pleuronectes platessa and cod Gadus morhua. Trans Am Fish Soc 114:499-506

Dalpadado P, Ellertsen B, Melle W, Dommasnes A (2000) Food and feeding conditions of Norwegian springspawning herring (Clupea harengus) through its feeding migrations. ICES J Mar Sci 57:843-857

* Daufresne M, Lengfellner K, Sommer U (2009) Global warming benefits the small in aquatic ecosystems. Proc Natl Acad Sci USA 106:12788-12793

* Dommasnes A, Melle W, Dalpadado P, Ellertsen B (2004) Herring as a major consumer in the Norwegian Sea. ICES J Mar Sci 61:739-751

Dormann CF, Schymanski SJ, Cabral J, Chuine I and others (2012) Correlation and process in species distribution models: bridging a dichotomy. J Biogeogr 39: $2119-2131$

№gesund O, Johannessen A, Ulltang Ø (1997) Variation in migration and abundance of Norwegian spring spawning herring (Clupea harengus L.). Sarsia 82:97-105

Eggers DM (1977) The nature of prey selection by planktivorous fish. Ecology 58:46-59

Elith J, Leathwick JR (2009) Species distribution models: ecological explanation and prediction across space and time. Annu Rev Ecol Evol Syst 40:677-697

Falkenhaug T (2016) Dyreplankton i Nordsjøen. In: Havforskningsrapporten 2016. Institute of Marine Research, Bergen, p 96-97

Fiksen O, Jørgensen C (2011) Model of optimal behaviour in fish larvae predicts that food availability determines survival, but not growth. Mar Ecol Prog Ser 432:207-219

Forster J, Hirst AG, Atkinson D (2012) Warming-induced reductions in body size are greater in aquatic than terrestrial species. Proc Natl Acad Sci USA 109: 19310-19314

Fransz HG, Colebrook JM, Gamble JC, Krause M (1991) The zooplankton of the North Sea. Neth J Sea Res 28: $1-52$

* García Molinos J, Halpern BS, Schoeman DS, Brown CJ and others (2016) Climate velocity and the future global redistribution of marine biodiversity. Nat Clim Chang 6 : 83-88

Gardner JL, Peters A, Kearney MR, Joseph L, Heinsohn R (2011) Declining body size: A third universal response to warming? Trends Ecol Evol 26:285-291

Ghalambor CK, McKay JK, Carroll SP, Reznick DN (2007) Adaptive versus non-adaptive phenotypic plasticity and the potential for contemporary adaptation in new environments. Funct Ecol 21:394-407
Gibson RN, Ezzi IA (1985) Effect of particle concentration on filter- and particulate-feeding in the herring Clupea harengus. Mar Biol 88:109-116

* Gislason A, Astthorsson OS (2002) The food of Norwegian spring-spawning herring in the western Norwegian Sea in relation to the annual cycle of zooplankton. Sarsia 87: 236-247

Guisan A, Zimmermann NE (2000) Predictive habitat distribution models in ecology. Ecol Modell 135:147-186

*Hare JA, Alexander MA, Fogarty MJ, Williams EH, Scott JD (2010) Forecasting the dynamics of a coastal fishery species using a coupled climate-population model. Ecol Appl 20:452-464

*Helenius LK, Borg JPG, Nurminen L, Leskinen E, Lehtonen $H$ (2013) The effects of turbidity on prey consumption and selection of zooplanktivorous Gasterosteus aculeatus L. Aquat Ecol 47:349-356

*Helmuth B, Kingsolver JG, Carrington E (2005) Biophysics, physiological ecology, and climate change: Does mechanism matter? Annu Rev Physiol 67:177-201

*Horne CR, Hirst AG, Atkinson D, Enquist B (2015) Temperature size responses match latitudinal size clines in arthropods, revealing critical differences between aquatic and terrestrial species. Ecol Lett 18:327-335

* Huse G, Fiksen Ø (2010) Modelling encounter rates and distribution of mobile predators and prey. Prog Oceanogr 84:93-104

* Huse G, Fernö A, Holst J (2010) Establishment of new wintering areas in herring co-occurs with peaks in the 'first time/repeat spawner' ratio. Mar Ecol Prog Ser 409: 189-198

ICES (2007) ICES FishMap: herring. ICES, Copenhagen. https://www.ices.dk/explore-us/projects/EU-RFP/EU\% 20Repository/ICES\%20FIshMap/ICES\%20FishMap\%20 species \%20factsheet-herring.pdf

* Johansen JL, Jones GP (2013) Sediment-induced turbidity impairs foraging performance and prey choice of planktivorous coral reef fishes. Ecol Appl 23:1504-1517

Jonasdottir SH, Koski M (2011) Biological processes in the North Sea: comparison of Calanus helgolandicus and Calanus finmarchicus vertical distribution and production. J Plankton Res 33:85-103

Jónasdóttir SH, Trung NH, Hansen F, Gärtner S (2005) Egg production and hatching success in the calanoid copepods Calanus helgolandicus and Calanus finmarchicus in the North Sea from March to September 2001. J Plankton Res 27:1239-1259

Jones MC, Cheung WWL (2015) Multi-model ensemble projections of climate change effects on global marine biodiversity. ICES J Mar Sci 72:741-752

Karplus I, Popper D, Goldan O (2000) The effect of food competition and relative size of group members on growth of juvenile gilthead sea bream, Sparus aurata. Fish Physiol Biochem 22:119-123

Kawecki TJ, Ebert D (2004) Conceptual issues in local adaptation. Ecol Lett 7:1225-1241

Kingsolver JG, Huey RB (2008) Size, temperature, and fitness: three rules. Evol Ecol Res 10:251-268

Kirk JTO (2011) Light and photosynthesis in aquatic ecosystems, $3^{\text {rd }}$ edn. Cambridge University Press, Cambridge

Kirtman B, Power SB, Adedoyin JA, Boer GJ and others (2013) Near-term climate change: projections and predictability. In: Stocker TF, Qin D, Plattner GK, Tignor M and others (eds) Climate change 2013: the physical science basis. Contribution of Working Group I to the Fifth 
Assessment Report of the Intergovernmental Panel on Climate Change. Cambridge University Press, Cambridge, p 953-1028

Kitano S (1996) Size-related factors causing individual variation in seasonal reproductive success of fluvial male Dolly Varden (Salvelinus malma). Ecol Freshwat Fish 5: 59-67

Kangbehn TJ, Varpe $\varnothing$ (2017) Sea-ice loss boosts visual search: fish foraging and changing pelagic interactions in polar oceans. Glob Change Biol 23:5318-5330

Langbehn TJ, Aksnes DL, Kaartvedt S, Fiksen Ø, Jørgensen C (2019) Light comfort zone in a mesopelagic fish emerges from adaptive behaviour along a latitudinal gradient. Mar Ecol Prog Ser 623:161-174

Last JM (1989) The food of herring, Clupea harengus, in the North Sea, 1983-1986. J Fish Biol 34:489-501

Lefevre S, McKenzie DJ, Nilsson GE (2017) Models projecting the fate of fish populations under climate change need to be based on valid physiological mechanisms. Glob Change Biol 23:3449-3459

Ljungström G, Francis TB, Mangel M, Jørgensen C (2019) Parent-offspring conflict over reproductive timing: ecological dynamics far away and at other times may explain spawning variability in Pacific herring. ICES J Mar Sci 76:559-572

McNab BK (2010) Geographic and temporal correlations of mammalian size reconsidered: a resource rule. Oecologia 164:13-23

Melle W, Ellertsen B, Skjoldal HR (2004) Zooplankton: the link to higher trophic layers. In: Skjoldal HR, Sætre R, Færnö A, Misund OA, Røttingen I (eds) The Norwegian Sea ecosystem. Tapir Academic Press, Trondheim, p 137-202

Michod RE (1979) Evolution of life histories in response to age-specific mortality factors. Am Nat 113:531-550

Millien V, Kathleen Lyons S, Olson L, Smith FA, Wilson AB, Yom-Tov Y (2006) Ecotypic variation in the context of global climate change: revisiting the rules. Ecol Lett 9: 853-869

Mobley CM (1994) Light and water: radiative transfer in natural waters. Academic Press, San Diego, CA

* Morel A (1991) Light and marine photosynthesis: a spectral model with geochemical and climatological implications. Prog Oceanogr 26:263-306

Pauly D (1981) The relationships between gill surface area and growth performance in fish: a generalization of von Bertalanffy's theory of growth. Meeresforschung 28: 251-282

Pearson RG, Dawson TP (2003) Predicting the impacts of climate change on the distribution of species: Are bioclimate envelope models useful? Glob Ecol Biogeogr 12: 361-371

Peterson I, Wroblewski S (1984) Mortality rate of fishes in the pelagic ecosystem. Can J Fish Aquat Sci 41: $1117-1120$

* Pitcher TJ, Magurran AE, Edwards JI (1985) Schooling mackerel and herring choose neighbours of similar size. Mar Biol 86:319-322

Pitois SG, Shaw M, Fox CJ, Frid CLJ (2009) A new fine-mesh zooplankton time series from the Dove sampling station (North Sea). J Plankton Res 31:337-343

Pörtner HO (2010) Oxygen- and capacity-limitation of thermal tolerance: a matrix for integrating climate-related stressor effects in marine ecosystems. J Exp Biol 213: 881-893
Richardson AJ, Schoeman DS (2004) Climate impact on plankton ecosystems in the Northeast Atlantic. Science 305:1609-1612

Roff D (1981) On being the right size. Am Nat 118:405-422

Roff DA (1992) The evolution of life histories: theory and analysis. Chapman Hill, New York, NY

Rudstam LG (1988) Exploring the dynamics of herring consumption in the Baltic: applications of an energetics model of fish growth. Kiel Meeresforsch, Sonderh 6: 312-322

Sarmiento JL, Slater R, Barber R, Bopp L and others (2004) Response of ocean ecosystems to climate warming. Global Biogeochem Cycles 18:GB3003

Schmidt-Nielsen K (1984) Swimming and flying. In: Scaling: why is animal size so important? Cambridge University Press, Cambridge, p 182-194

Schmidt-Nielsen K (1997) Movement, muscle, biomechanics. In: Animal physiology: adaptation and environment, $5^{\text {th }}$ edn. Cambridge University Press, p 395-464

* Segers F, Dickey-Collas M, Rijnsdorp AD (2007) Prey selection by North Sea herring (Clupea harengus), with special reference to fish eggs. ICES J Mar Sci 64:60-68

Sheridan JA, Bickford D (2011) Shrinking body size as an ecological response to climate change. Nat Clim Chang 1:401-406

Skjoldal HR (2004) The Norwegian Sea ecosystem. Tapir Academic Press, Trondheim

Slotte A (1999) Differential utilization of energy during wintering and spawning migration in Norwegian springspawning herring. J Fish Biol 54:338-355

Slotte A, Fiksen O (2000) State-dependent spawning migration in Norwegian spring-spawning herring. J Fish Biol 56:138-162

Sørnes TA, Aksnes DL (2004) Predation efficiency in visual and tactile zooplanktivores. Mar Biol 49:69-75

Stearns SC (1992) The evolution of life histories. Oxford University Press, Oxford

Steinacher M, Joos F, Frölicher TL, Bopp L and others (2010) Projected 21st century decrease in marine productivity: a multi-model analysis. Biogeosciences 7:979-1005

Teplitsky C, Millien V (2014) Climate warming and Bergmann's rule through time: Is there any evidence? Evol Appl 7:156-168

Thuiller W, Münkemüller T, Lavergne S, Mouillot D, Mouquet N, Schiffers K, Gravel D (2013) A road map for integrating eco-evolutionary processes into biodiversity models. Ecol Lett 16:94-105

Urban MC, Bocedi G, Hendry AP, Mihoub JB and others (2016) Improving the forecast for biodiversity under climate change. Science 353:aad8466

Utne ACW (1997) The effect of turbidity and illumination on the reaction distance and search time of the marine planktivore Gobiusculus flavescens. J Fish Biol 50: 926-938

* Utne-Palm AC (1999) The effect of prey mobility, prey contrast, turbidity and spectral composition on the reaction distance of Gobiusculus flavescens to its planktonic prey. J Fish Biol 54:1244-1258

van Deurs M, Christensen A, Frisk C, Mosegaard H (2010) Overwintering strategy of sandeel ecotypes from an energy/predation trade-off perspective. Mar Ecol Prog Ser 416:201-214

*van Deurs M, Jorgensen C, Fiksen O (2015) Effects of copepod size on fish growth: a model based on data for North Sea sandeel. Mar Ecol Prog Ser 520:235-243 
Varpe $\varnothing$ (2017) Life history adaptations to seasonality. Integr Comp Biol 57:943-960

Varpe $\varnothing$, Fiksen $\varnothing(2010)$ Seasonal plankton-fish interactions: light regime, prey phenology, and herring foraging. Ecology 91:311-318

Varpe $\varnothing$, Daase M, Kristiansen T (2015) A fish-eye view on the new Arctic lightscape. ICES J Mar Sci72: 2532-2538

Verberk WCEP, Bilton DT, Calosi P, Spicer JI (2011) Oxygen supply in aquatic ectotherms: partial pressure and solubility together explain biodiversity and size patterns. Ecology 92:1565-1572

Vinarski MV (2014) On the applicability of Bergmann's rule to ectotherms: the state of the art. Biol Bull Rev 4: 232-242

Vinyard GL, O'Brien WJ (1976) Effects of light and turbidity on the reactive distance of bluegill (Lepomis macrochirus). J Fish Res Board Can 33:2845-2849

Voss KJA (1992) Spectral model of the beam attenuation

Editorial responsibility: Myron Peck,

Hamburg, Germany coefficient in the ocean and coastal areas. Limnol Oceanogr 37:501-509

*Waples RS, Audzijonyte A (2016) Fishery-induced evolution provides insights into adaptive responses of marine species to climate change. Front Ecol Environ 14:217-224

WWare DM (1978) Bioenergetics of pelagic fish: theoretical change in swimming speed and ration with body size. J Fish Res Board Can 35:220-228

Watt C, Mitchell S, Salewski V (2010) Bergmann's rule; A concept cluster? Oikos 119:89-100

Whitehead PJP (1985) FAO species catalogue, Vol 7: clupeoid fishes of the world (suborder Clupeoidei). An annotated and illustrated catalogue of the herrings, sardines, pilchards, sprats, shads, anchovies and wolf-herrings. FAO Fisheries Synopsis No. 125. FAO, Rome

*Wilson RJ, Speirs DC, Heath MR (2015) On the surprising lack of differences between 2 congeneric calanoid copepod species, Calanus finmarchicus and C. helgolandicus. Prog Oceanogr 134:413-431

Submitted: September 25, 2019; Accepted: January 20, 2020 Proofs received from author(s): February 14, 2020 